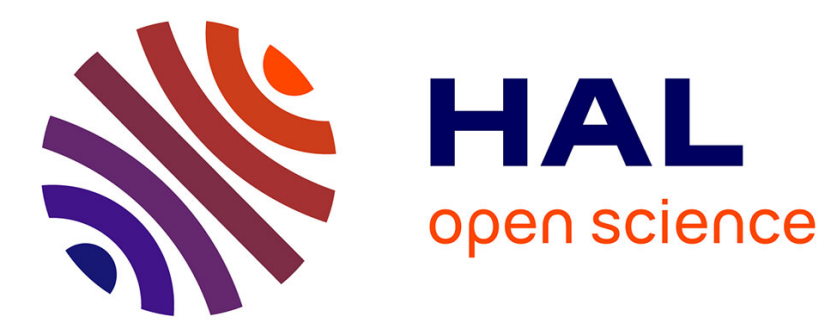

\title{
TRIZ - Develop or Die in a World Driven by Volatility, Uncertainty, Complexity and Ambiguity
}

Martin Kiesel, Jens Hammer

\section{To cite this version:}

Martin Kiesel, Jens Hammer. TRIZ - Develop or Die in a World Driven by Volatility, Uncertainty, Complexity and Ambiguity. 18th TRIZ Future Conference (TFC), Oct 2018, Strasbourg, France. pp.55-65, 10.1007/978-3-030-02456-7_5 . hal-02279774

\section{HAL Id: hal-02279774 \\ https://hal.inria.fr/hal-02279774}

Submitted on 5 Sep 2019

HAL is a multi-disciplinary open access archive for the deposit and dissemination of scientific research documents, whether they are published or not. The documents may come from teaching and research institutions in France or abroad, or from public or private research centers.
L'archive ouverte pluridisciplinaire HAL, est destinée au dépôt et à la diffusion de documents scientifiques de niveau recherche, publiés ou non, émanant des établissements d'enseignement et de recherche français ou étrangers, des laboratoires publics ou privés.

\section{(c)(1)}

Distributed under a Creative Commons Attribution| 4.0 International License 


\title{
TRIZ - Develop or Die in a World Driven by Volatility, Uncertainty, Complexity and Ambiguity
}

\author{
Martin Kiesel ${ }^{1[0000-1111-2222-3333]}$ and Jens Hammer ${ }^{2[1111-2222-3333-4444]}$ \\ ${ }^{1}$ Siemens AG, Erlangen, DF MC TTI, Germany \\ ${ }^{2}$ School of Business and Economics, Friedrich-Alexander-Universität Erlangen-Nürnberg \\ Incsespringer. com
}

\begin{abstract}
In industry, companies must face the need for increasing developing speed in a volatile and uncertain market environment. Digitalization, cloud computing and artificial intelligence introduce a game changing situation. Classical TRIZ was derived from patent analysis, based on technical/mechanical problem solving. There is a bunch of methods and tools available for these issues. However, in a VUCA (Volatility, Uncertainty, Complexity, Ambiguity) world we face situations which are increasingly complex and potentially require different approaches. The paper discusses to which extent the TRIZ methods and tools are helpful in a VUCA world and how TRIZ should develop to adapt to the changing environment. The authors investigate where TRIZ can provide helpful directions and in which dimensions it should evolve. A potential "TRIZ Picture of the Future" is developed based on literature review and long-term experiences in Lean development, TRIZ and foresight technologies.
\end{abstract}

Keywords: TRIZ, VUCA, TESE, Cynefin Framework, Three-Layered Product Architecture.

\section{$1 \quad$ Introduction}

In industry, companies must face the need for increasing developing speed in a volatile and uncertain market environment. We live in a world where companies must reinvent faster than ever before. Digitalization, cloud computing and artificial intelligence introduce a game changing situation. In the last 15 years, $52 \%$ of the fortune 500 companies have disappeared. In contrast, classical TRIZ was derived from patent analysis, based on technical/mechanical problem solving. There is a bunch of methods and tools available for these issues. However, in a VUCA (Volatility, Uncertainty, Complexity, Ambiguity) world we face situations which are increasingly complex and potentially require different approaches. In the VUCA World which is more or less addressing software, the development approaches are moving to Lean, Agile, Design Thinking, User Experience and other methodologies. The paper discusses to which extent the TRIZ methods and tools are helpful in a VUCA world and how TRIZ should develop to fit into the changing environment. The authors investigate where classic and modern TRIZ can provide helpful directions and in which dimensions TRIZ should evolve. A potential "TRIZ Picture of the Future" based on literature 
review and long-term experiences in Lean development, TRIZ and foresight technologies was derived.

\section{$2 \quad$ Literature Review}

\subsection{Changing Environment}

"Across many industries, a rising tide of volatility, uncertainty, and business complexity is roiling markets and changing the nature of competition.' [1].

New technologies are changing industry boundaries and the nature of products, processes and services (e.g. competitive landscape raised by digitalization and Industrie 4.0) [2]. There had been clearly different industries, businesses and customer needs in the education, communication and entertainment markets, for example [2]: the consumer electronics industry (including television and other audio/video products); the computer business (including desktop pcs, laptops and video consoles); the communication devices industry (smartphones); the software business; the music industry and the movie industry [2]. 20 years ago, each of these industries and businesses had its individual established competitors and competitive dynamics [2]. It was an ecosystem of certainty in which features, and functionality was embedded in the product and developed in relatively known steps. Digitization has empowered industries and products to combine features and functions in many new ways [2]. Over a long period of time, companies have seen technological skills such as miniaturization as one of their core competences [2]. From that perspective, portability was the primary benefit afforded the customer by miniaturization, and companies set their focus of innovation in the product space [2]. Therefore, the goal was to maximize that benefit by making as many products as possible smaller and lighter. But nowadays the consumer perspective might frame the challenge differently [2].

Employing an acronym for volatility, uncertainty, complexity, and ambiguity (VUCA), organizations have asserted that we now live in a 'VUCA world' [2]. This generates different traps for companies, leaders and employees in the business environment. Volatility is expressing unclear, unforeseeable and fast changing market conditions. Where uncertainty is addressing user acceptance of implemented features or user acceptance of new business model, complexity is related to the complex development condition (teams worldwide, new technologies). Ambiguity is focusing on unclear directions, no stable forecasting and unclear cause effect chains. However, optimists see the opportunities a company can achieve, if its leaders master the accompanying challenges. For example [3]:

- Volatility provides profit opportunity [4]

- Uncertainty is an opportunity [5]

- Simplifying IT complexity is a major opportunity for all companies [6]

- Ambiguity equals opportunity [7] 
Nevertheless, volatility and uncertainty increase the demand for short development times and customer driven development. Complexity is addressing a higher system knowledge and partner approaches. Especially regarding ambiguity, there is a high need for experimentation. Only though, intelligent experimentation can determine, what is valued by the customer and beneficial for the company and what not. In the VUCA World the development approaches are moving to Lean, Agile, Design Thinking, User Experience and other methodologies.

\section{$2.2 \quad$ Evolution of TRIZ}

The TRIZ methodology was derived from the analysis of the world patent collection [9] and established a bunch of tools shown in figure 1 (frequently used tools MATRIZ). These tools cover, problem identification (analysis), problem solving (ideation), forecasting for technical evolutions and solutions selection. TRIZ provides different methods for these processes (e.g. technical and physical contradictions for modelling of inventive problems) and forecasting methods like 9-Window or TESE (Trends of Engineering System Evolution).

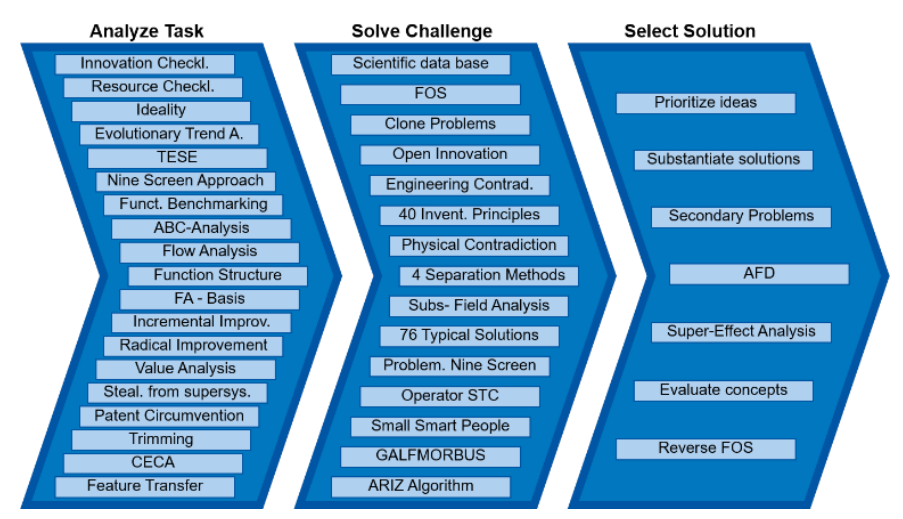

Fig. 1. Classification of TRIZ tools $[9,10]$

The methodology has always had a strong focus on identifying available resources in the environment especially in the super-system which might support the problem solving. In recent years the TRIZ toolset increases its portfolio and its application fields. However, within TRIZ, the product and potential next development steps are main reasons for its application. Moreover, the main application field is for hardware development or optimization.

TRIZ and the related tool set developed over years. Different research contributions show first steps for a shift from hardware to software products and services. The latest TRIZ developments have extended the scope of TRIZ from 
technical systems to business systems [11] and introduced extended fields:

- Voice of the product

- Voice of the market

- Voice of the business

Based on this, new tools emerged addressing "blocking contradictions" [11] on this extended field:

- Value-Conflict Mapping (VCM) [12]

- Value-Conflict Mapping Plus (VCM+) [13]

These tools expand the scope of analysis and contradiction resolving process by considering the entire business system comprising [11]:

- $\quad$ products (classical TRIZ) with value proposition and goods \& services

- business organization and ecosystem with the business requirements and the approach the product is brought to market

- market with market requirements, market methods and customers \& users

Boka (2017) applied the TRIZ method in business systems combining TRIZ with the Value Proposition Model of Osterwalder [11, 16] which sets the customer into the center emphasizing pains, gains and customer jobs as a starting point for improvements and innovations.

"Human interactions" is another area where TRIZ is evolving. Mayer (2016) extended the existing trends by the "Trend of Increased Addressing of Human Senses" proposing to incorporate the near field senses like Sensing, Tasting and Smelling into the TESE toolbox $[14,15]$. Sun $[25,26]$ integrated user information into the design process to solve contradictions in product usage. The focus on human interactions fits perfectly to the increasing focus of user experience (UX) in products and services of a VUCA environment. Functional completeness is not enough in a VUCA world - user experience becomes more and more important. Boka (2017) used new resources like a "data crawler" which presented a proxy to social media platforms like Facebook \& Google [11]. These platforms provided social media knowledge which was used to solve the inventive problems. Litvin (2017) [17] provides in his paper "Open Innovation: TRIZ Approach vs. Crowdsourcing" [17] key principles for efficient usage of open innovation. "First, focus on key problems, not on initial ones. Second search on functions not on specific designs."

In "Main Parameters of Value (MPV): TRIZ-based Tool Connecting Business Challenges to Technical Problems in Product/Process Innovation" [18] Litvin (2018) provides approaches how MPVs can be used to develop a business with a clear direction. This can also be incorporated into a Lean development setup. 
Halas (2016) investigated the combination of TRIZ, Design Thinking (DT) \& Lean [19]. He concluded, that TRIZ supplements these tools by providing methods and tools for the ideation phase [19]. DT and Lean tools provide approaches for human interaction, empathy, experimentation and for getting fast feedback from the customer. According to Abramov [8], other creativity approaches like Design Thinking become more popular then TRIZ in a Lean and Agile development environment. Moreover, there is a higher demand for customer driven and customer focused methods.

\section{Methodology}

For a structured discussion the authors used a Cynefin Framework and a Three-Layer Product Model to characterize the status of the TRIZ methodology and derive actions. The Cynefin Framework [20] is a reference for classification of system / problem types and Three-Layer Product Model of Jan Bosch [21] supports in discussion with an architecture model for products \& services in a VUCA world.

\section{Introduction of Cynefin Framework as a reference for classification of problem} types

Dave Snowden provides with the Cynefin Framework (see Figure 2, [20]) a generic framework which classifies systems / problems and provides approaches how to deal with them.

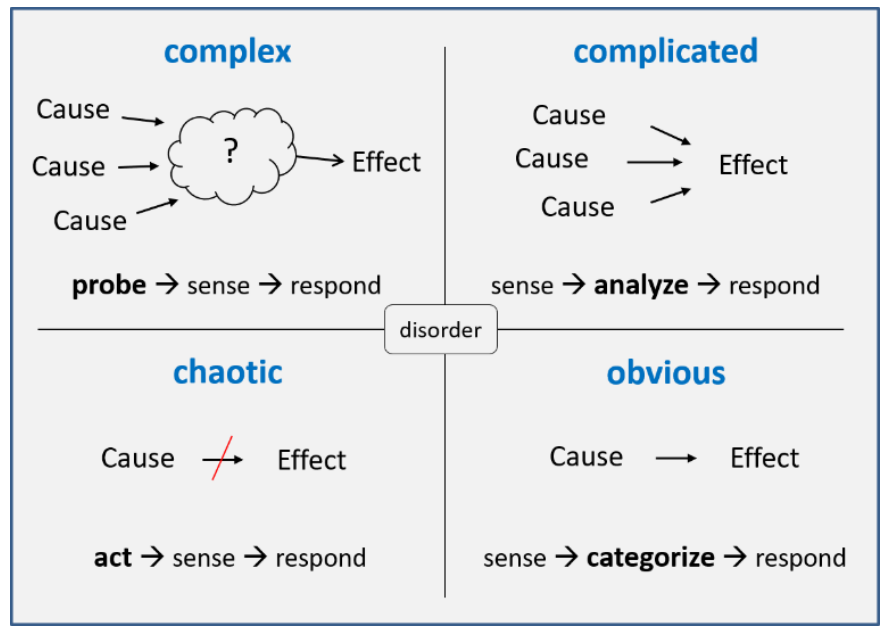

Fig. 2. Cynefin Framework [20] 
The classification defines obvious problems, complicated problems, complex problems and chaotic ones.

Simple problems show a clear cause - effect relation. Complicated problems require a more analytical view on the system. Complex problems have no clear analyzable cause-effect-chain. For chaotic problems the Framework recommends fast acting without any analyzing. The disorder area tags systems/problem which can't be clearly classified and mapped to one of the four areas.

\section{Introduction of Three-Layer Product Model as an architecture model for prod- ucts \& services in a VUCA world}

Bosch (2017) recommends a Three-Layer Product Model which provides a solution approach for addressing different needs in a VUCA word (see figure 3) [21]. The product architecture is divided into three layers (innovative principle \#1: segmentation).

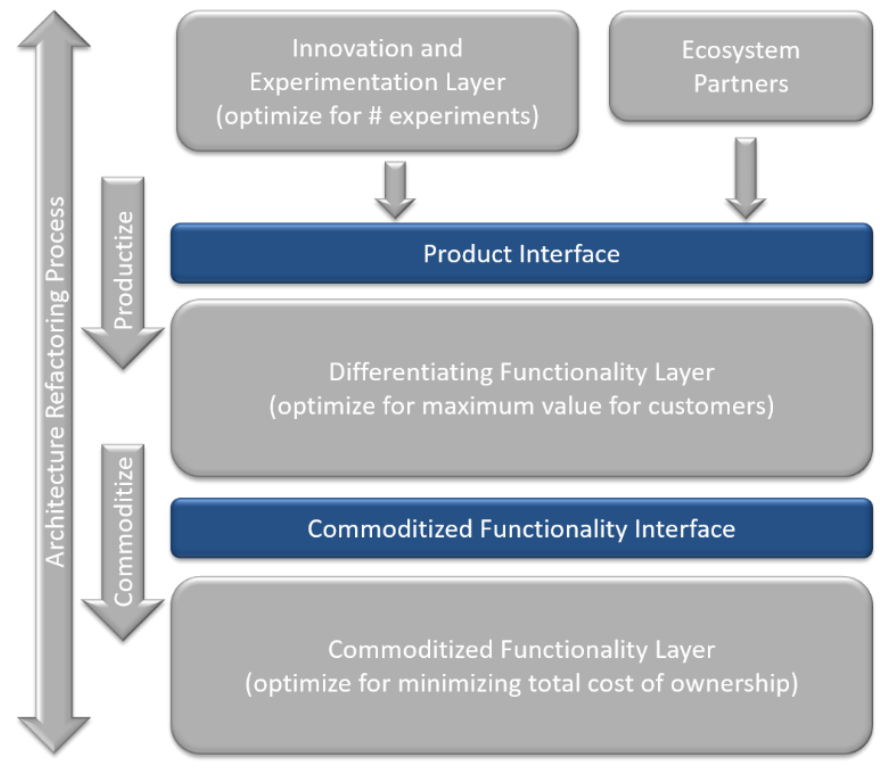

Fig. 3. Three-Layer Product model (Jan Bosch) [21]

The lowest layer covers the Commoditized Functionality. The major optimization criteria for this layer is cost. The usage of open source and components of the shelf (COTS) is strongly recommended. 
The middle layer covers the Differentiation Functionality. This is the area where the Unique Selling Proposition (USP) is in. The major investment should be focused in this area.

The highest layer represents the Innovation and Experimentation Layer. This Layer is optimized to run as many experiments as possible at the lowest possible costs.

The product provides interfaces to Ecosystem partners. This integration allows the leverage of ecosystems for raising the overall value of the product. This kind of architecture supports speed, keeps the USP of a product in a dedicated layer and leverages existing resources like Open Source, Components of the Shelf (COTS) and ecosystems to the best possible extent. According to the model there are continuous Architecture Refactoring measures in place to move the functionality from the top layer to the bottom layer of the Architecture over time. New valuable functionality explored in the Innovation Layer moves to the Differentiating Layer. USP Features of the Differentiating Layer move to the Commodized Layer when the functionality is regarded as Standard and is no longer a USP of the product.

For each of the identified discussion areas we used reflection of the current state and definition of the target state to verify the current status and derive possible next development steps. The current and target state are based on a literature review and trends in research development.

\section{$4 \quad$ Results and Discussion}

In a VUCA (Volatility, Uncertainty, Complexity, Ambiguity) world we face situations which are increasingly complex and potentially require different approaches. Regarding a picture of the future of TRIZ and its further development, especially volatile and uncertain markets/outcomes and the product complexity are key drivers. The introduced Cynefin Framework and a Three-Layer Product Model lead to the following findings regarding the classification of problems and the product model.

\section{Cynefin Framework}

Simple problems show a clear cause - effect relation. Rational judgement is the proposed way to find a suitable measure for solving the problem. TRIZ and its 40iP are appropriate to solve the problem. However, other classical tools are suitable as well.

Complicated problems require a more analytical view on the system. There are typically several causes for an effect. These kinds of problems can be analyzed by e.g. Root Cause Analysis (RCA). Classical TRIZ analysis tools focus on complicated problems which can be covered with analytical tools.

Complex problems have no clear analyzable cause-effect-chain. They require a different solution approach like building a hypothesis of a possible solution and testing it. Analytical approaches based on theory are not suitable. This is the typical area of uncertainty about the right solution in a VUCA World. The complex problems can't be analyzed with analytical tools without experiments. TRIZ foresight tools like 9- 
Screen Approach or TESE provide helpful directions for deriving solution hypothesis which are beyond obvious solution approaches derived from brainstorming and can be used in this area as well.

For chaotic problems the Framework recommends fast acting without any analyzing. The disorder area tags systems/problem which can't be clearly classified and mapped to one of the four areas.

The transfer of problems from a complex space to the complicated and then simple domain can be supported by TRIZ integrating the newly explored findings and successful integration of new technologies into the existing TRIZ knowledge base (e.g. adding new innovation principles, new resources (which can solve the problems), or new Trends of Engineering System Evolution) Moreover, there is an option to extend the scope of TRIZ (e.g. from products to services, Approaches to include new business models, customer interaction and feedback).

\section{Three Layer Product Model}

The Three Layer Product model shows, that TRIZ tools can be applied to support the evolution process in different ways (e.g. supporting the problem analysis process with RCA, identifying contradictions in the current product architecture, formulating necessary functions and searching with Function Oriented Search (FOS)). Generating a Picture of the Future for the Product is addressing the changing environment by using Ideality, 9 Screen Approach and TESE and deriving requirements for the next evolution step of the product architecture might generate additional value.

Moreover, the authors recommend discussing the areas (1) application fields, (2) technical, (3) ecosystem resources and (4) TRIZ in a Lean \& Agile working environment.

The application field describes areas in which TRIZ methods and tools should be used to cover the demands of the VUCA world. Resources play a big role in the TRIZ toolset and are one basis of the methodological approach.

Besides the Cynefin Framwork and the Three Layer Product Model, we see further key topics to develop TRIZ in a VUCA world, in Application Fields, Technical and Ecosystem Resources and working models.

\section{Application Fields:}

Currently, TRIZ tools focus on technical systems and technical processes. Regarding future requirements, the methodology needs to extend its scope to the following aspects, which are to some extend already in development or addressed in some articles:

- technical systems with increasing Software, human interaction and IT-related aspects and technologies (e.g. cloud computing, blockchain,...)

- business systems / business models

- $\quad$ service oriented business models (covering the Trend from products to services)

- User Experience related aspects (potentially in combination with DT approaches) 
- Emergent optimization of the product architecture to cover new upcoming demands (e.g. based on the Three-Layer Product Model [21])

This extended scope is necessary to cover todays demands. The intention / philosophy of the existing TRIZ tools are still valid for instance for key problem analysis, required function analysis for function oriented search, formulating of contradictions. The Tools like function analysis must be extended to cover this wider scope.

\section{Technical and Ecosystem Resources:}

The current scope regarding technical resources is based on elementary effects (i.e. physical, chemical, biological). They are often abbreviated with "MATCHEMIB". It is an acronym for the eight TRIZ-"fields": mechanical, acoustic, thermal, chemical, electric, magnetic, intermolecular and biological. Although the fields of MATCHEMIB were introduced as stimuli during the idea generation phase of Substance-Field Analysis, they can be used on their own.

Regarding the successes in sensors and new application fields there is a need for development. Especially Data (Data Analytics) in the field of cloud computing, artificial intelligence and deep learning is a new upcoming resource which must be covered in the future.

Ecosystems are part of the super-system. Regarding the target scope relevant ecosystems should be visible as resources (e.g. digital platforms from Microsoft Azure and Amazon AWS or open source assets available at the marketplace)

\section{TRIZ in a Lean \& Agile working environment}

Currently, there are some guidelines how to apply TRIZ in an iterative and timeboxed driven environment $[17,18]$.

Solution algorithms like ARIZ are complex and are rarely used in Lean development setups. Moreover, retrospectives and incremental improvements concerning the application of TRIZ are not established.

In [24], the authors investigated the opportunities of integrating TRIZ into the large scale Agile software development Framework (SAFe). They propose to apply TRIZ to drive innovation on different layers of the Framework (Portfolio, Program and Team level).

One target of TRIZ in a Lean \& Agile working environment is, according to the authors, that MPV-usage and -thinking is deeply integrated in the Lean development process. MPV can be used to define the overall project goals. MPVs serve as a frame for unfolding the intended values into specific Epics in a Product Backlog). TRIZ is heavily used in suggesting solution alternatives especially "disruptive" approaches derived from TESE or radical trimming changing the problem situation. TRIZ usage and further development is driven by retrospectives optimizing the application of TRIZ. And moreover, TRIZ is used and accepted as a learning \& thinking tool for accelerated learning on team and/or project level. Iteration is key for a development in an uncertain world. Analysis of key problems, formulation of necessary functions (for 
function oriented search) are still very important, but early user centric testing and feedback becomes more and more important for early verification of feature hypothesis.

\section{Conclusion}

TRIZ has already developed in different application fields and optimized the known toolset. However, there is a need for improvement regarding the authors "TRIZ - Picture of the Future". In total, the picture of the future covers four main areas. These are further application fields of TRIZ, new resources, simplification of the application of TRIZ and foster emergent development.

To cover the complete value of a product or service, technical systems need to include increasing Software, human and IT-driven aspects. Business systems and business models should be considered in the TRIZ approach. User Experience including human interactions and IT areas (Software, internet-related areas, e.g. ecosystems, cloud computing) need to be addressed to cover the complete value proposition of the product or service. Moreover, there is a need to adapt tools to cover the extended scope and for solving complex problems with experimental approaches.

The incorporation of new resources is necessary to stay relevant for current developments. New technical and ecosystem resources have to be established.

Moreover, there is a need for simplification of the applicability of TRIZ. The incorporation of Lean practices for improvement and further development (e.g. use retrospectives) will help to reflect and improve the application of TRIZ.

Finally, we have to foster emergent development of TRIZ. TRIZ has to move from centralized driven development (Altshuller, TRIZ Master) to decentralized, autonomous, operational driven development, with clear focus (success criteria) on "value add" for innovation speed and quality in a VUCA world.

Figure 4 summarizes the ideas of the "TRIZ Picture of the Future".

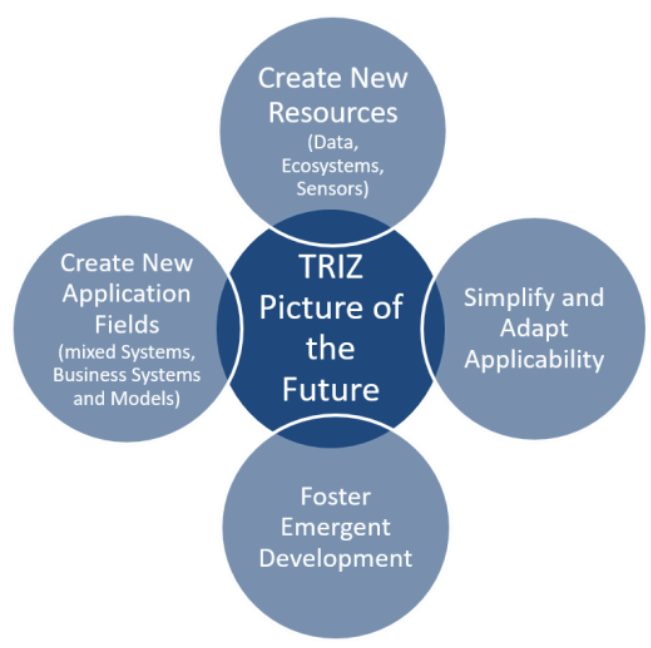

Fig. 4. TRIZ Picture of the Future 


\section{References}

1. Doheny, M., Nagali, V., \& Weig, F. (2012, May). Agile operations for volatile times. McKinsey Quarterly. Retrieved from https://www.mckinsey.com/businessfunctions/operations/our-insights/agile-operations-for-volatile-times

2. Bennett, N., \& Lemoine, G. J. (2014). What a difference a word makes: Understanding threats to performance in a VUCA world. Business Horizons, 57(3), 311-317.

3. Prahalad, C. K., \& Ramaswamy, V. (2003). The new frontier of experience innovation. MIT Sloan management review, 44(4), 12-18.

4. Warwick-Ching, L. (2013, March 25). Currency wars: Volatility provides profit opportunity. The Financial Times. Retrieved from https://www.ft.com/content/e17e1ab0-8714-11e29dd7-00144feabdc0

5. Hemingway, A., \& Marquart, J. (2013, June 27). Uncertainty is opportunity: Engage with purpose. Edelman. Retrieved from http://www.edelman.com/post/uncertainty-isopportunity-engage-with-purpose/

6. Boston Consulting Group. (2013, March 21). Simplifying IT complexity a major opportunity for many companies [Press Release]. Retrieved from http://www.bcg.com/media/Press ReleaseDetails.aspx?id=tcm:12-130333

7. Amerasia Consulting Group. (2013, June 3). Ambiguity equals opportunity: The story of the new HBS application. Retrieved from http://www.amerasiaconsulting.com/blog/2013/6/3/ ambiguity-equals-opportunity-thestory-of-the-new-hbs- application

8. Abramov, O., Sobolev, S., 2016, Why TRIZ Popularity is Declining. TRIZ Future conference, Wroclaw, Poland.

9. Ikovenko, S. and Bradley, J., 2004, February. TRIZ as a lean thinking tool. In 4th TRIZ Future Conf., Florence, Italy.

10. Adunka R. MA TRIZ Level 1 Training: Script; 2015; triz-online.de. (2014). TRIZ online. Retrieved 05/30, 2014, from http://www.triz-online.de/

11. Boka, Siarhei, Kuryan Andrei, Ogievich Dmitry, Applications of TRIZ in Business Systems. TRIZfest 2017. Krakow, Poland.

12. Souchkov V.http://www.xtriz.com/publications/Souchkov_Value_Conflict_Mapping.pdf

13. Kurjan, A., Souchkov V. Value-Conflict Mapping Plus (VCM+): Adding Business Dimensions. TRIZfest-2014 conference proceedings.

14. Mayer, O. Trend of Increased Addressing of Human Senses - Focus on Near Senses". TRIZ Etria Conference 2016. Wroclaw, Poland.

15. Mayer, O. "Increased Adressing of Human Senses as a Trend". TRIZfest 2017, Krakow, Poland.

16. Osterwalder, A, Pigneur Y. Value Proposition Design: How to Create Products and Services Customers Want. Wiley, 2014.

17. Litvin, S. Rutten, P. “Open Innovation: TRIZ Approach vs. Crowdsourcing”. TRIZfest 2017, Krakow, Poland.

18. Litvin .S. 2011. Main Parameters of Value: TRIZ-based Tool Connecting Business Challenges to Technical Problems in Product/Process Innovation. Retrieved 03/16, 2018 from http://www.triz-japan.org/PRESENTATION/sympo2011/Pres-Overseas/EI01eSLitvin_(Keynote)-110817.pdf 
19. Halas, M. Lessons for TRIZ from Design Thinking \& Lean 3P. TRIZ Future conference 2016. Wroclaw, Poland.

20. Snowden, D. The Cynefin Framework. http://www.cognitive-edge.com

21. Bosch, J. https://www.researchgate.net/publication/260584542_ Achieving _ Simplicity_with_the_Three-Layer_Product_Model

22. Kiesel, M., Hammer, J. Applying TRIZ and Lean Tools for Improving Development Processes. A Case Study from Industry: Improving the Testing Process for SW and HWrelated Products. TRIZ Future 2016, Wroclaw, Poland

23. Hammer, J., Kiesel, M. Applying TRIZ to improve Lean Product Lifecycle Management Processes. TRIZfest 2017, Krakow, Poland

24. Opportunities for integrating TRIZ and systematic innovation tools into large scale Agile software development. TRIZ Future conference 2016. Wroclaw, Poland.

25. Xiaoguang Sun et. Al. Integrating User Information into Design Process to Solve Contradictions in Product Usage. TRIZ Future conference 2015. https://www.sciencedirect.com/science/article/pii/S2212827116001980

26. Xiaoguang Sun et. Al. Innovative interaction design approach based on TRIZ separation principles and inventive principles. TRIZ Future converence 2017. Lappeenranta, Finland.

27. Houssein Remy et. Al. Fostering continuous innovation in design with an integrated knowledge management approach. Computers in Industry. Volume 62, Issue 4, May 2011, Pages 423-436 